\title{
Forecasting on China's Labor Supply and Demand Gap during 2018-2035
}

\author{
Li Sun*, Kai Sun, Hongxiao Zhang and Jinchu Zhou \\ School of Information, Beijing Wuzi University, Beijing, China \\ ${ }^{*}$ Corresponding author
}

\begin{abstract}
Keywords: Labor supply and demand; Coefficient of Increased Employment; ARIMA model; Technological progress
\end{abstract}

\begin{abstract}
Based on the changing discipline of labor participation proportion in different age groups rule and the prediction results of future population structure and total amount by using Leslie model, this paper estimates the labor supply of working-age population in China from 2018 to 2035. In addition, based on the analysis of time series model, this paper predicts the change of labor demand in China from 2018 to 2035. The influence of technological progress is considered in the process of forecasting labor demand. The forecasting results show that the gap between supply and demand of labor force in China will be widen in the near future. Finally, this paper puts forward some suggestions on how to guarantee the supply of labor force in China in the aspects of population policy, retirement policy, industrial structure reform and education system.
\end{abstract}

\section{Introduction and Related Works}

At present, with the original high-speed growth turning to medium-high-speed growth in Chinese economic situation, employment pressure is growing. From the 1980s to the end of 2014, Chinese working-age population accounted for more than $66.7 \%$ of the total population. There is a shortage of labor supply in recent years in China, which may be severer in the future. According to the Statistical Bulletin of National Economic and Social Development in 2018, Chinese working-age population at the end of 2018 showed a decrease of 4.7 million people compared with the end of 2017. According to the forecast of the Ministry of Human Resources and Social Security in 2018, by 2050, the population of working-age will fall to about 700 million. It can be predicted that if we do not take certain measures, the demand for labor will exceed the supply in the future, and the situation of labor shortage will become more and more serious. At present, domestic scholars mainly study the supply and demand of labor force in the following four aspects:

Firstly, from the perspective of the impact of economic factors on employment, this paper studies the current employment trend and the relationship between economic growth and employment in China. M.Z. Qi [1] used various forecasting methods to study the relationship between economic factors and labor supply and demand.

Secondly, from the perspective of Chinese population, Z.Y. Guo and W.J. Jin [2] analyzed China's labor market problems, and concluded that the employment situation is extremely severe and difficult to solve.

Thirdly, it studies the labor participation rate which is closely related to the supply of labor force. There are differences in labor participation rate between urban and rural areas in China, and rural labor participation rate is higher than urban areas. S.P. Yan [3] (2016) found that the rapid decline in employment rate is mainly due to the premature withdrawal of urban residents from the labor market.

Fourthly, from other perspectives, Scholars study the influencing factors of the labor market. C.W. Zhang and Y.F. Cai [4] used various methods to forecast the situation of labor supply and demand in China, and got the conclusion that labor supply and demand showed a balance. According to an article by China Daily, Chinese working-age population will drop to 700 million by 2050 . 


\section{Research Methods}

For the prediction of labor supply, this paper adopts the method of analyzing influencing factors and setting reasonable labor participation rate; for the prediction of labor demand, this paper uses the defined Coefficient of Increased Employment and time series model to predict. Finally, we find the potential dangers and contradictions that may exist in the future labor market of China by the analysis of the forecast results of labor supply and demand, and put forward targeted policy recommendations.

The main innovation of this study is to use the Coefficient of Increased Employment in this paper to establish a time series model to forecast. This coefficient is the ratio of labor demand to real GDP, which is different from the Coefficient of Employment Elasticity (the ratio of labor demand to real GDP growth rate). Compared with the Coefficient of Employment Elasticity, the change range of Coefficient of Increased Employment is gentler and more stable, which is conducive to the construction of the model.

\section{Leslie Population Forecasting Model}

This paper considers that the Leslie population prediction model has the advantages of high prediction accuracy, which is suitable for large-scale prediction. It is very suited for the future population prediction of the country.

Considering the female fertility rate varies greatly every year, two factors of fertility model and total fertility rate are introduced to establish the model.

$$
N_{0}(\mathrm{k}+1)=\beta(\mathrm{k}+1) \sum_{i=b_{1}}^{b_{2}} h_{i} m_{0} N_{i}(\mathrm{k}+1) \frac{100}{100+c(\mathrm{k}+1)}
$$

$N_{i}(\mathrm{k}+1)=m_{i} N_{i-1}(\mathrm{k}), 1 \leq i \leq 100$

Notes: $\beta(\mathrm{k}+1)$ : the total fertility rate of the first $\mathrm{k}+1$ year; $h_{i}$ : the fertility mode of the female at the age of $\mathrm{i} ; N_{i}(\mathrm{k}+1)$ : the number of the population at the age of $\mathrm{i}$ at the age of $\mathrm{k}+1$ year; $m_{i}$ : the survival rate of the population at the age of $\mathrm{i} ; c(\mathrm{k}+1)$ : the sex ratio at the age of $k+1$ year.

\section{ARIMA Model}

ARIMA model is a well-known time series prediction method and a combination of AR model and MA model. The formula is as follows:

$$
y_{t}=\mu+\sum_{i=1}^{p} \phi_{i} y_{t-i}+\varepsilon_{t}-\sum_{i=1}^{q} \theta_{i} \varepsilon_{t-i}
$$

\section{Estimation of Labour Supply}

\section{Estimation of Labor Participation Rate}

According to the results of two censuses and the data of China Statistical Yearbook at the end of 2017, it is found that Chinese labor participation rate changed dramatically in 2000 and 2010, and the labor participation rate of all age groups showed a significant downward trend. What influences china's labor participation rate? Y.Y. Wang and Y.F. Tong [5] (2015) used the quantitative regression analysis method to obtain four factors that significantly affect the labor participation rate in China. According to the regression results, $\mathrm{F}$ value has passed the significance test, which shows that independent variables and dependent variables have good correlation and explanatory ability. If other conditions remain unchanged, "the proportion of population aged 25-44 (logarithm)," GDP growth rate (logarithm)" and "the proportion of added value of the tertiary industry in GDP (logarithm)" increases by 1 percentage point, the labor participation rate will increase by $0.504 \%$, $0.053 \%$ and $0.040 \%$;"the enrollment scale of ordinary universities (logarithm)"will increase by 1 
percentage point, and the labor participation rate will increase by $0.504 \%, 0.053 \%$ and $0.040 \%$. It will decrease by $0.085 \%$.

This paper makes a reasonable prediction or hypothesis about the future labor participation rate of all age groups in order to estimate the future labor supply more accurately. This study refers to the hypothetical conclusions of X.L. Liu and S.Y. Wang [6] (2018) on Chinese labor participation rate from 2018 to 2025. The accuracy of the results of the sixth census (2010) is higher than that of the 2018 China Statistical Yearbook. Considering the law of diminishing marginal utility (the labor participation rate of the adolescent population will not decline indefinitely), this paper argues that the decline rate of the labor participation rate of the 15-19 and 20-24-year-olds will slow down slightly in 2026-2035. They found that in order to compensate for the shortage of labor supply, China is actively pursuing the policy of delayed retirement. Therefore, it is assumed that the labor participation rate of 50-54, 55-59 and 60-64 years old population in 2018-2025 will increase by $0.22 \%, 0.2 \%$ and $0.18 \%$ annually on the basis of the 2010 census data. This paper holds that with the improvement of Chinese social security system, the improvement of people's living standards and the improvement of Chinese labor productivity in the future, the rising rate of the labor participation rate of the elderly will gradually slow down in the future.

\section{Estimation of Chinese Population Structure in the Future}

According to the calculation of Chinese scholars, the total fertility rate in China has stabilized around 1.60 after 2010. This paper assumes that the total fertility rate changes after the implementation of the two-child policy. From 2018 to 2020, China is in the initial response stage to the two-child policy. The total fertility rate rises to 1.70. The total fertility rate is 1.65 in 2021-2025 and 1.60 in 2026-2035. For the survival rate, this paper uses the data of the sixth census to calculate the mortality rate of each age group, and then obtains the results of the survival rate of each age group. The survival rate of the future age groups set in 2010 and this paper is obtained. For the sex ratio, according to the sex ratio data collected from the statistical yearbooks of past years, through the use of male and female data modeling, fitting and screening, the best fit is selected. The linear model with the highest $\mathrm{R}$ square (0.967 and 0.961 ) has been used to predict the future sex ratio in China.

The parameters of Leslie model are substituted into the model to predict the future population size and structure in China.

\section{Estimating Chinese Labor Supply in the Future}

Based on the forecasted labor participation rate of different age groups in China from 2018 to 2035 and the forecasted results of the structure and scale of Chinese working-age population in corresponding years, according to the nature of labor participation rate, this paper calculates the forecasted results of Chinese labor supply from 2018 to 2035 in Figure 1.

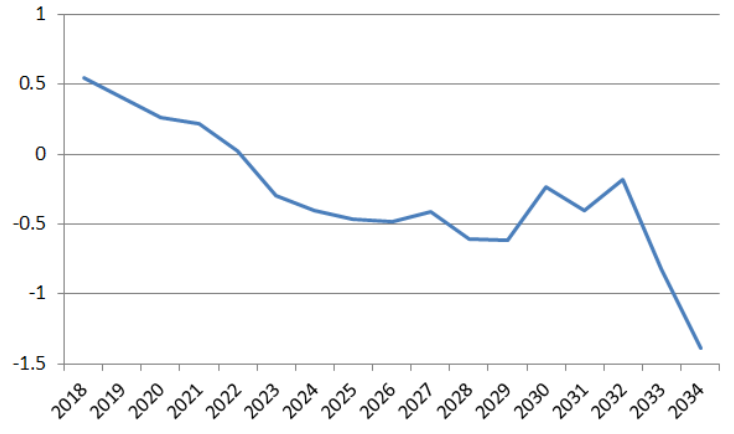

Figure 1. Growth rate of China's labor supply

\section{Calculation Results and Analysis}

The analysis and forecast results show that the overall labor supply in China has a significant downward trend, and the total labor force decreased from 74.84 million in 2018 to 71.51 million in 2035. In 2035, Chinese 25-29-year-old labor force changed the most, increasing by about 10 million people; in 2023, the change was the smallest, with a change rate of $2.2 \%$, which increased by only 
170,000 people compared with the previous year. The labor force aged $45-49$ increased the most, by 21.23 million people. This reflects the aging phenomenon of Chinese labor force in the future.

\section{Forecast of Future Labour Demand}

GDP is the most important factor affecting employment demand. M.J. Shao et al. [7] (2018) made a short-term GDP forecast for China. They thought that the GDP growth rate of China was 6.06\% in 2019 and $5.07 \%$ in 2020, which is about $0.45 \%$ lower than the previous year. According to the growth rate of China at the end of 2018, the forecast is too conservative. Our country's 13th Five-Year Plan target and forecast center forecast the future GDP growth rate of our country. According to the assumption, the average annual growth rate of GDP is 6.5\% in 2016-2020, 6.1\% in 2021-2025, 5.5\% in 2026-2030 and 5\% in 2031-2040. Compared with the growth rate of $6.3 \%$ at the end of 2018, this forecast is more in line with the law of GDP growth and change in China.

To sum up, this paper assumes the following assumptions for Chinese future GDP growth: the average annual GDP growth rate is 6.3\%, 5.5\% and 5\% in the period of 2019-2025, 2026-2030 and 2031-2035, respectively, to calculate the real GDP based on 1978 in 2018-2035.

\section{Forecasting Chinese Labor Demand in the Future Based on ARIMA Model}

Definition of Employment Pull Coefficient. This paper defines a new employment pull coefficient, which is set as the ratio of labor demand to real GDP. Its significance is to reflect the pulling effect of GDP on Chinese employment. Firstly, the historical employment pull coefficient (1978-2017) is calculated, and ARIMA model is fitted according to its law and forecasted. The employment pull coefficient in 2018-2035 is obtained. What's more, according to the employment pull coefficient and the forecast result of real GDP in the future, the forecast result of labor demand is obtained.

Data Sources and Preprocessing. The data in this paper are derived from the current GDP of 1978-2017 in China Statistical Yearbook and the labor force of 10,000 people in China Labor Statistical Yearbook. The current GDP is converted into real GDP of 1978-2017 through GDP index to fit labor demand.

Model Fitting. Through unit root test and differential processing, the autocorrelation and partial correlation diagrams of time series data are analyzed, and the parameters $\mathrm{p}$ and $\mathrm{Q}$ of ARIMA model are selected. The models with different parameters $\mathrm{p}$ and $\mathrm{Q}$ are constructed respectively, and then the best model for each group of time series data is selected by using AIC information criterion. According to AIC criteria and SC criteria, ARIMA $(1,1,0)$ is selected as the model in this study.

By calculating, the predicted value of time series is obtained, and the error is calculated. As shown in Table 6, the fitting effect of this model is better. The relative error of data in 2015-2017 is less than $6.1 \%$, and the mean of relative error of data in $1980-2017$ is $3.91 \%$, which shows that the fitting result of this model is remarkable. Through the nature of the employment pull coefficient and the real GDP forecast above, we can calculate the forecast value of the future labor demand of our country as Figure 2 shows.

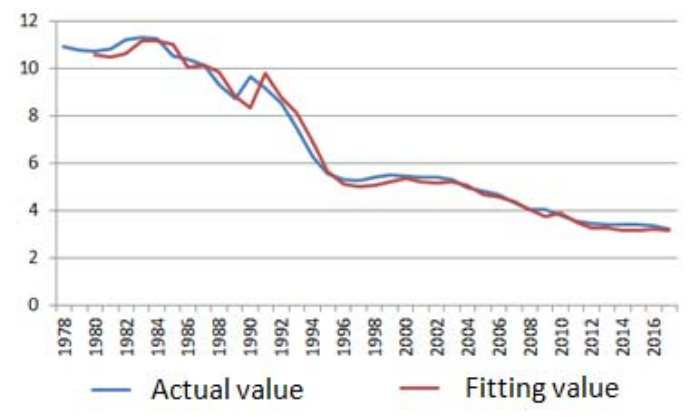

Figure 2. Model fitting

The Impact of Technological Advances on Chinese Labor Demand Model Fitting. Suppose the forecasting result above without considering the impact of technological progress is scenario 
one. If we consider the impact of technological progress on it, we need to consider the two roles of employment creation and employment substitution. The creative effect of technological advances such as artificial intelligence on labor force is influenced by economic factors, but its substitution effect on labor force still needs further quantitative research.

Especially in the robot market, in recent years, a series of industry policy subsidies have been issued by the state policy. The State Council issued "Made in China 2025", in which the robot industry is one of the most beneficiary industries. The number of industrial robots in China reached 256,000 in 2015, 317,000 in 2016 and 423,000 in 2017. It can be seen that in recent years, the number of industrial robots in China has grown very fast.

According to the change rule of employment pull coefficient used in the previous paper, the definition of employment pull coefficient has included the influence of economic factors on labor demand, that is, technology factors are included in economic factors, so the creative effect of technological progress on labor force is not considered. According to the research of $\mathrm{H}$. Cheng et al. [8], there is a quantitative substitution relationship between robots and Chinese labor force: on the premise of fully eliminating other characteristic factors, the average substitution effect of the current density of robots on the non-skilled labor force of the experimental group (using robots) enterprises is about $2.9 \%$. That is to say, the use of robots will reduce the non-skilled labor force of the above enterprises by about 2.9\%. According to the current number of workers in China, this paper assumes that the substitution rate of robots for workers (substitution rate $=$ substituted workers /industrial robots) is $825.15 \%$.

According to the data provided by CRIA [9], this paper summarizes the growth law of the number of industrial robots in China in recent years, uses SPSS software to fit the cumulative installation curve model of industrial robots, obtains the future supply of industrial robots, and calculates the number of industrial robots in China in the future according to the 10-year depreciation cycle of machinery (i.e., the average depreciation rate of robots in China is $10 \%$ ). In the future, the number of industrial robots in China will increase dramatically. By 2035, the number of industrial robots in China is expected to be 1.925 million. Therefore, considering the substitution role of robots in the future, we assume that the labor demand of our country will increase linearly in the future.

\section{Model Results and Discussion}

Compared with the predicted results of Chinese labor supply gap from Figure 3, we can see that:

The forecasting results of this paper show that the labor shortage will exist persistently in China from 2018 to 2035. According to the result of scenario one, there is a predicament of insufficient supply in China from 2018. The gap between supply and demand of labor force reaches 10.877 million, reaching a peak of 28.467 million by 2034, and the gap between supply and demand of labor force will reach 22.623 million by 2035. According to the forecasting results of scenario 2, the annual labor supply and demand gap is slightly lower than scenario 1. In 2018, Chinese labor supply and demand gap was 17.96 million, while in 2035, the gap expanded to 19.52 million. In the future, Chinese labor force gap is relatively large, which must be paid enough attention by the relevant departments.

Secondly, technological advances such as machines and artificial intelligence must be supported by corresponding policies in order to avoid their destructive effect on employment outweighing the creative effect. At the same time, as the driving force of Chinese economic growth, the progress of technological makes it creating greater demand for labor in the labor market in terms of creating new jobs and improving social labor productivity. 


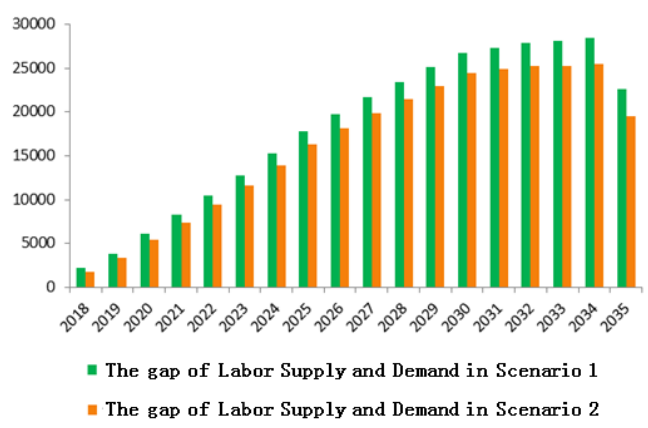

Figure 3. Two scenarios forecasting the labor supply and demand gap in China from 2018 to 2035.

\section{Policy Recommendations}

We need to persist the comprehensive liberalization of the two-child policy. At the present stage, Chinese infant population occupies a huge proportion, which promote the effect. It can be expected that China will produce more people of working-age in the future, which will make the labor market more balanced and become a surging driving force to promote economic growth.

With the further development of compulsory education and the increasing demand for high-quality talents, more and more young workers will receive higher education. So that the proportion of young labor force will decline in the future and the middle-aged labor force remains stable. Therefore, in order to meet the needs of the labor market in China, we can only take certain measures for the elderly population. So it is beneficial to adopt a policy of postponing retirement age.

Through industrial restructuring, we can promote agricultural modernization, which will reduce the demand for rural labor force, develop high-end industries and reduce the demand for simple and repetitive labor force in the labor market. At the same time, we should improve and upgrade the middle and low-end labor market, and deepen the reform of the labor supply side.

There are not only contradictions between supply and demand of labor force, but also challenges of employment growth brought by the transformation of old and new momentum in China's labor market. At present, there is a big gap between Chinese labor skill level and the United States'. In order to enhance international competitiveness, China should recognize the gap between education and international advanced level, and cultivate more innovative and skilled talents to meet the growing needs of the people for a better life.

\section{Acknowledgments}

This project was funded by 2018 "Practical Training" Project of High-level Talents Cross-cultivation in Beijing Universities and Colleges, Beijing Intelligent Logistics System Collaborative Innovation Center (PXM2018_014214_000009), Beijing Key Laboratory (BZ0211).

\section{References}

[1] M.Z. Qi, “Forecast of China's labor supply and demand from 2010 to 2050”. Population Research, vol. 34, pp.76-87, 2010.

[2] Z.Y.Guo, W.J. Jin. Employment, "Employment situation and employment countermeasure in population perspective”, Northwest Population,vol 31,pp. 109-112,2010.

[3] S.P. Yan, "Changes and determinants of urban and rural employment rate in China --Empirical analysis based on data from 1988-2010 China Urban Income Survey”, Labor Economic Research, vol. 4, pp. 83-102, 2016.

[4] C.W. Zhang, Y.F. Cai, "China's labor supply and demand forecast and gap analysis during the 13th Five-Year Plan period”. Population Research, vol. 40, pp. 38-56, 2016. 
[5] Y.Y Wang, Y.F. Tong. “The impact of China's aging population on labor participation,” Journal of Capital University of Economics and Trade, vol. 17, pp. 61-67, 2015.

[6] X.L. Liu, S.Y. Wang, "A study on the measurement of labor supply by age groups in China from 2018 to 2025 under the background of the Two-Child policy," Science and Technology for Development,vol. 14 ,pp. 17-22, 2018

[7] M.J. Shao, Z.Z. Ren, Z.H. Zhao and T. Guo, “ARIMA model in Chinese GDP forecast,” Value Engineering, vol. 37, pp. 205-207, 2018.

[8] H. Cheng, W.J. Chen, T. Li, "Robots in China: current situation, future and impact - Empirical evidence from CEES,” Macro Quality Research, vol. 6, pp. 1-21, 2018.

[9] W.L. Liang, “Statistical analysis of Chinese industrial robot market,” Robot Technology and Applications, vol. 2,pp. 42-48, 2019. 